\title{
Raman Scattering and Electronic Spectra of Poly(acetylene)
}

\author{
Hideki Shirakawa, Takeo Ito, and Sakuji Ikeda \\ Research Laboratory of Resources Utilization, Tokyo Institute of Technology, \\ 12-1, 2-Chome, Ookayama, Meguro-ku, Tokyo 152, Japan.
}

(Received August 17, 1972)
KEY WORDS Poly(acetylene) / Polyene / Raman Spectra / Elec- tronic Spectra / Configuration / cis-Opening /

The normal vibrations of infinite linear trans and cis (cis-transoid or trans-cisoid)-poly(acetylene) can be treated under a factor group which is isomorphous to the point group $\mathrm{D}_{2 \mathrm{~h}}{ }^{1}$. When the trans molecule has bond alternation and carbon-carbon bonds being unequal in length, symmetry of the molecule belongs to a factor group which is isomorphous to the point group $C_{2 b}$. Since both $C_{2 h}$ and $D_{2 b}$ symmetries have a center of inversion, a vibrational mode may be active in the infrared but not in the Raman and vice versa.

Raman scattering supplies new vibrational informations which can not be obtained by infrared measurements. Thus, symmetric carboncarbon stretching vibrations which are active in Raman may give more informations about the configuration of main chain and alternation of the carbon-carbon bonds in the poly(acetylene) or linear polyene chain.

Laser-Raman spectra in the region of 2000$500 \mathrm{~cm}^{-1}$ were recorded on the Japan Electron Optics Laboratory Model JRS-C1 laser-excited spectrometer. Raman spectra of poly(acetylene) films were obtained by the front surface reflection method in which the sample was mounted at $45^{\circ}$ inclination to the incident beam. The $632.8 \mathrm{~nm}$ line of a $\mathrm{He}-\mathrm{Ne}$ laser, having an output power of $c a .30 \mathrm{~mW}$, was used as the Raman source. An argon ion laser at either 488.0 or $514.5 \mathrm{~nm}$ was also used occasionally. In this case, the output power was attenuated as weak as possible in order to prevent the isomerization reaction of the cis-poly(acetylene) to trans form from a heating effect due to the laser radiation.

The Raman scattering spectrum of all trans

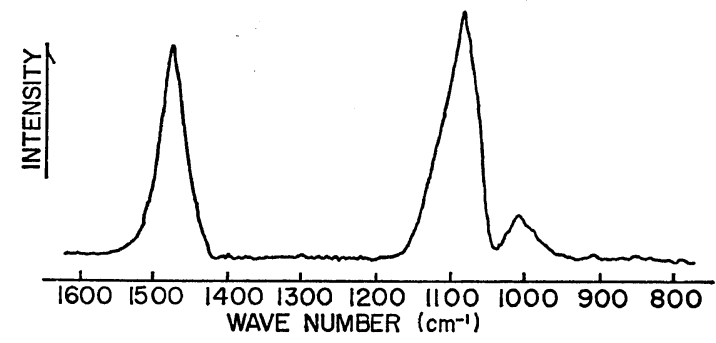

Figure 1. Raman spectrum of trans-poly(acetylene): excitation, at $632.8 \mathrm{~nm}$; slit width, $8 \mathrm{~cm}^{-1}$; scan speed, $25 \mathrm{~cm}^{-1} / \mathrm{min}$.

poly(acetylene) is shown in Figure 1. Two strong bands at 1474 and $1080 \mathrm{~cm}^{-1}$ and a weak band at $1016 \mathrm{~cm}^{-1}$ were observed. Figure 2 shows the Raman scattering of all cis-poly(acetylene) prepared at $-78^{\circ} \mathrm{C}$. Although the infrared spectrum of the cis polymer shows a very weak band at $1015 \mathrm{~cm}^{-1}$ which is assigned to trans $\mathrm{C}-\mathrm{H}$ out-of-plane deformation vibration, trans bands at about 1500, 1100, and $1016 \mathrm{~cm}^{-1}$ besides cis bands at 1552, 1262, and $920 \mathrm{~cm}^{-1}$, are observed distinctly in the Raman spectrum. It is considered that a heating effect due to the laser radiation causes irreversible cis-trans isomerization to yield the trans configuration during the measurements. High frequency shifts of the trans bands in the cis-poly(acetylene) may be due to the short sequences formed by partial cistrans isomerization. When a strong argon ion laser at $488.0 \mathrm{~nm}$ was used as Raman source, the heating effect was too strong to observe the cis bands (Figure 2, curve 3).

The trans-poly(acetylene) film is an intense black material with a metallic luster, whereas the cis- 


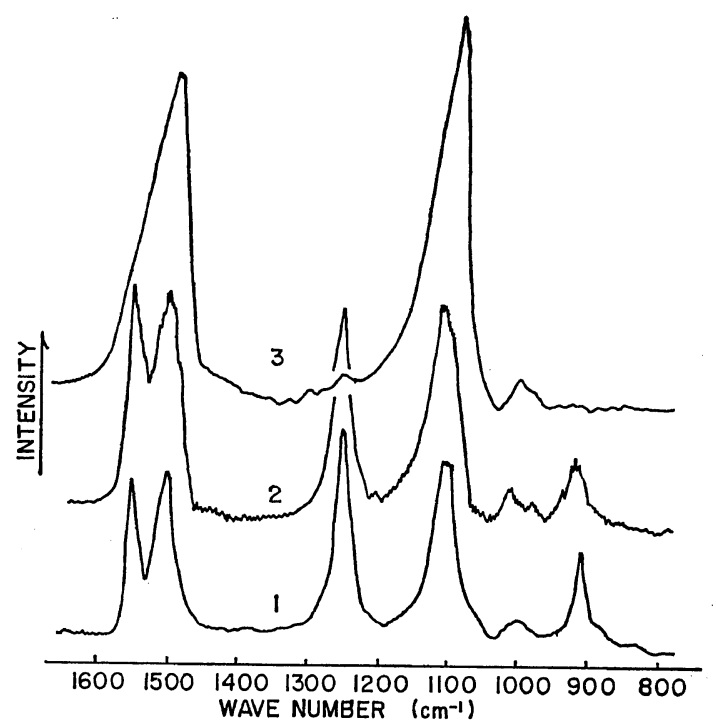

Figure 2. Raman spectra of cis-poly(acetylene): (1) excitation at $632.8 \mathrm{~nm}$; slit width, $8 \mathrm{~cm}^{-1}$; scan speed, $25 \mathrm{~cm}^{-1} / \mathrm{min}$; (2) excitation at $514.5 \mathrm{~nm}$; slit width, $12 \mathrm{~cm}^{-1}$; scan speed, $25 \mathrm{~cm}^{-1} / \mathrm{min}$; (3) excitation at $488.0 \mathrm{~nm}$; slit width, $14 \mathrm{~cm}^{-1}$; scan speed, $25 \mathrm{~cm}^{-1} / \mathrm{min}$.

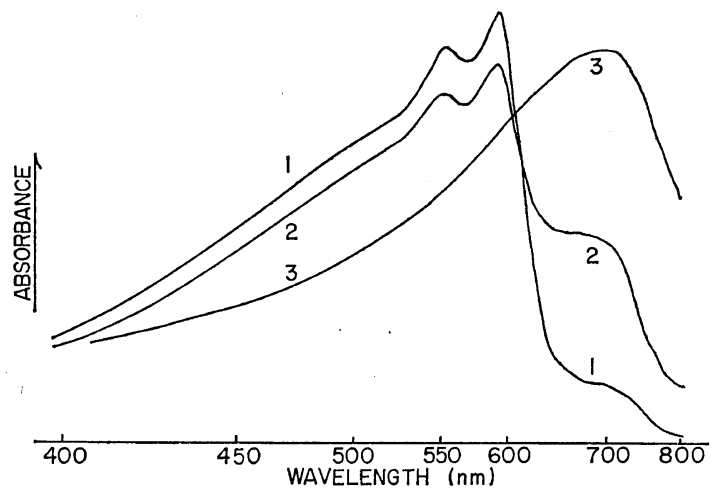

Figure 3. Electronic spectra of poly(acetylene): (1) cis-poly(acetylene) prepared at $-78^{\circ} \mathrm{C}$; (2) cis-poly(acetylene) partly isomerized at $110^{\circ} \mathrm{C}$ for $3 \mathrm{~min}$; (3) completely isomerized to trans-poly(acetylene) at $180^{\circ} \mathrm{C}$ for $2 \mathrm{~min}$.

polyacetylene film has a copper-like luster. Very thin films of trans and cis polymers show deep blue and clear red colours, respectively. Figure 3 shows the electronic spectra of poly(acetylene) in which the cis and trans contents are varied. The spectra were obtained for an extremely thin film which was polymerized at $-78^{\circ} \mathrm{C}$ on the inside wall of $1-\mathrm{cm}$ quartz cell and isomerized in situ by heating with an oil bath. Strong absorptions due to the lowest $\pi \rightarrow \pi^{*}$ transition were observed in the visible region with miximum at $594 \mathrm{~nm}$ for an all cis polymer and at $700 \mathrm{~nm}$ for an all trans polymer.

As expected from a great number of electronic spectra of conjugated linear polyenes which are shown by general formula such as $\mathrm{H}(\mathrm{CH}=\mathrm{CH})_{n} \mathrm{H}$ $\left(n=3,5,6,8\right.$, and 10), ${ }^{4} \mathrm{CH}_{3}(\mathrm{CH}=\mathrm{CH})_{n} \mathrm{CH}_{3}(n=$ $3-9),{ }^{5} \quad \mathrm{C}_{6} \mathrm{H}_{5}(\mathrm{CH}=\mathrm{CH})_{n} \mathrm{C}_{6} \mathrm{H}_{5} \quad(n=1-7),{ }^{6} \quad$ and carotenoides, ${ }^{7}$ the wavelength of absorption becomes progressively longer as the length of the conjugated chain is extended. The longest linear polyene having known structure is dodecapreno$\beta$-carotene ${ }^{7}$ which has nineteen conjugated double bonds and exhibits an absorption maximum at $531 \mathrm{~nm}$ in petroleum ether.

According to the simple free-electron model ${ }^{13}$ or LCAO molecular orbital theory, ${ }^{14}$ the transition energy between the highest occupied and the lowest vacant level tends to zero for an infinitely long polyene which has no bond alternation, thus the wavelength should become infinite. H. Kuhn, ${ }^{8}$ however, found that the observed wavelength could only be interpreted by the free-electron theory if the bond length were supposed to alternate throughout the chain, even in very long chains. Kuhn, ${ }^{8}$ Dewar, ${ }^{9}$ and Streitwieser ${ }^{10}$ presented values of 622,536 , and $583 \mathrm{~nm}$, respectively, as the convergent values for the infinitely long polyene in which the bond alternation was assumed. Although a large number of linear conjugated polyenes have been discussed by many investigators, synthetic and isolated natural polyenes as well as those subjected to the theoretical studies are usually in the all trans form, and there are few reports on the all cis long polyenes. However, as shown for the all trans polyenes, the tendency for the wavelength to approach a finite value with increasing chain length may also be expected for the all cis polyenes. The convergent wavelength may be shorter than the corresponding value of the all trans polyene, because the degree of the $\pi$-electron localization or bond alternation in the all cis form is stronger than in the all trans form due to the twisting around the single bond caused by the steric repulsion between the two hydrogen atoms located in every other double 
bond along the all cis sequence. The degree of polymerization or the number of conjugation of poly(acetylene), however, is not known at the present time; the polymers prepared under different conditions give the maximum at the same wavelength. The wavelength at 594 and $700 \mathrm{~nm}$ for cis and trans-poly(acetylene), respectively, may be the convergent values for the lowest $\pi \rightarrow \pi^{*}$ transition of linear conjugated cis and transpolyenes.

The observation of intense Raman bands may be attributed to the resonance-enhancement effect which is observed when the exciting frequency approaches or enters the region of electronic absorption of the molecule. Since the electronic absorption in the visible region may be due to $\pi \rightarrow \pi^{*}$ transition between the highest occupied and the lowest vacant $\pi$ orbitals in the polymer, enhanced-Raman active modes depend on the contribution of the carbon-carbon single and double bond stretching vibrations. Similarity of the spectral features with those of carotenoide, $\beta$-carotene $\left(1527\right.$ and $\left.1158 \mathrm{~cm}^{-1}\right)$ and lycopene $\left(1516 \text { and } 1156 \mathrm{~cm}^{-1}\right)^{2}$ and the electronic spectrum suggest an alternation of double and single bond in the trans poly(acetylene). Thus, the 1474 and $1080 \mathrm{~cm}^{-1}$ bands are tentatively assigned to carbon-carbon double and single bond stretching vibrations, respectively.

Ivanova, Yanovskaya, and Shorygin ${ }^{11}$ have reported the Raman spectra of polyenedicarboxylic acid diethyl esters $\left(\mathrm{C}_{2} \mathrm{H}_{5} \mathrm{OOC}(\mathrm{CH}=\mathrm{CH})_{n}\right.$ $\left.\mathrm{COOC}_{2} \mathrm{H}_{5} n=1-8\right)$. They observed two strong bands at about 1600 and about $1140 \mathrm{~cm}^{-1}$. Frequencies of the band in the region of double bond stretching vibration decrease gradually from $1664 \mathrm{~cm}^{-1}$ for $n=1$ to $1540 \mathrm{~cm}^{-1}$ for $n=8$. The $1140 \mathrm{~cm}^{-1}$ band also shows a slight decrease from $1210 \mathrm{~cm}^{-1}$ for $n=1$ to $1137 \mathrm{~cm}^{-1}$ for $n=8$. The same tendency is observed for diphenylpolyenes $^{12}$ (1567 and $1145 \mathrm{~cm}^{-1}$ for $n=5,1552$ and $1142 \mathrm{~cm}^{-1}$ for $n=6$ ) and carotenoides. ${ }^{2}$ Lower frequency shifts in poly(acetylene) indicate that the number of conjugation in poly(acetylene) is longer than that of lycopene $(n=13)$.

Factor group modes of cis polymer are distributed among the symmetry species as $4 \mathrm{Ag}+$ $\mathrm{B}_{1} \mathrm{~g}+4 \mathrm{~B}_{2} \mathrm{~g}+2 \mathrm{~B}_{3} \mathrm{~g}+2 \mathrm{Au}+3 \mathrm{~B}_{1} \mathrm{u}+\mathrm{B}_{2} \mathrm{u}+3 \mathrm{~B}_{3} \mathrm{u}$ in which Raman active species are $\mathrm{Ag}, \mathrm{B}_{1} \mathrm{~g}, \mathrm{~B}_{2} \mathrm{~g}$, and $B_{3} g$. The result of analysis indicates that there are one $\mathrm{Ag}$ carbon-carbon double bond stretching and two corbon-carbon single bond stretching modes, one is $\mathrm{Ag}$ and the other $\mathrm{B}_{2} \mathrm{~g}$ in cis-transoid configuration; whereas polymer of trans-cisoid configuration has two carboncarbon double bond stretching modes, one is $\mathrm{Ag}$ and the other $\mathrm{B}_{2} \mathrm{~g}$, and one $\mathrm{Ag}$ carboncarbon single bond stretching mode. Since the spectrum of the cis polymer indicates one double bond stretching at $1552 \mathrm{~cm}^{-1}$ and two single bond stretching vibrations at 1262 and $920 \mathrm{~cm}^{-1}$, it can be concluded that configuration of the cis polymer is cis-transoid. The result confirms the previous work ${ }^{1}$ that the cis-opening of triple bond occurs in a polymerization reaction of acetylene with $\mathrm{Ti}\left(\mathrm{OC}_{4} \mathrm{H}_{9}\right)_{4}-\mathrm{Al}\left(\mathrm{C}_{2} \mathrm{H}_{5}\right)_{3}$ catalyst system at low temperatures.

Acknowledgment. The authors wish to express their indebtedness to Associate Professor S. Maeda of the Tokyo Institute of Technology and to Associate Professor M. Tasumi of the University of Tokyo for helpful discussions.

\section{REFERENCES}

1. H. Shirakawa and S. Ikeda, Polymer J., 2, 231 (1971).

2. L. Rimai, R. G. Kilponen, and D. Gill, $J$. Amer. Chem. Soc., 92, 3824 (1970).

3. D. J. Berets and D. S. Smith, Trans. Faraday Soc., 64, 823 (1968).

4. F. Sondheimer, D. A. Ben-Efraim, and R. Wolovsky, J. Amer. Chem. Soc., 83, 1675 (1961).

5. F. Bohlman and H. Manhardt, Chem. Ber., 89, 1307 (1956).

6. K. H. Hausser, R. Kuhn, and A. Smakula, $Z$. Phys. Chem., B29, 384 (1935).

7. P. Karrer and C. Eugster, Helv. Chim. Acta, 34, 1805 (1951).

8. H. Kuhn, J. Chem. Phys., 17, 1198 (1949).

9. M. J. S. Dewar, J. Chem. Soc., 3544 (1952).

10. A. Streitwieser, Jr., "Molecular Orbital Theory," John Wiley and Sons, Inc., New York, N.Y. 1961.

11. T. M. Ivanova, L. A. Yanovskaya, and P. P. Shorygin, Opt. Spectroscopy, 18, 75, (1965).

12. P. P. Shorygin and T. M. Ivanova, Soviet Phys., Doklady, 8, 493 (1963).

13. N. S. Bayliss, J. Chem. Phys., 16, 287 (1948).

14. J. E. Lennard-Jones, Proc. Roy. Soc. (London), A158, 280 (1937). 